\title{
Repercusiones organizacionales del nuevo modelo del Estado
}

Diego Escobar Alvarez*

* Profesor y Director del Postgrado en Administración Pública de la

Universidad del Valle 



\section{UN NUEVO MODELO DE ESTADO}

La crisis del Estado contemporáneo ha generado a nivel mundial un retorno a las fuentes del liberalismo clásico que encarna la recuperación del individualismo como esencia de la sociedad y al mercado, correlato económico de esta concepción filosófica, como supremo dispensador y regulador de los recursos productivos y sociales. Es el Estado Neoliberal, como comúnmente se le denomina, que desde la década de los 70's ha venido irrumpiendo en todas las sociedades, derrumbando barreras en todas las ideologías e imponiendo sus predicados en diversas latitudes, con tal fuerza que hoy ya prácticamente no se discute sobre su oportunidad o conveniencia, pues ha tomado tal dinámica de inevitabilidad, que la discusión versa hoy sobre el rigor, el grado o la intensidad de su aplicación. Este cambio de dirección en la concepción filosófica y el sistema económico de la sociedad conlleva no sólo profundas transformaciones en el Estado, sus fines, sus estructuras, sus funciones y su tamaño, sino también en la relación de lo público y lo privado, ampliando la esfera de lo privado en detrimento de lo público y, fundamentalmente, de lo estatal.

El Estado Intervencionista clásico y el modelo recortado de Estado de Bienestar implementado en nuestros países en vía de desarrollo, también conocido como la versión cepalina del Estado Neoestructuralista, que daba vigencia al Estado como agente económico productor y distribuidor de bienes y servicios y también como planificador y promotor del desarrollo. Además, a medida que ampliaba su intervención o manipulación del mercado le recortaba espacio a la esfera de lo privado y convertía lo público en estatal por la vía del incrementalismo de funciones, coberturas, organismos y burocracia, en un grado tal que el ciudadano, para el ejercicio cotidiano de sus actividades e interacciones sociales, se topaba siempre con el Estado a través de diversas manifestaciones de regulación. limitación, tramitación, obligación, manipulación e incluso coacción. 
Claro está que en el caso colombiano se presenta una situación dual, pues mientras que en ciertos segmentos sociales y geográficos hay un peso asfixiante del Estado, en otros, la sociedad civil no siente su presencia y se encuentra marginada social, económica y políticamente, dejando un vacío que ha sido copado por otras "expresiones de legitimidad" como la guerrilla, el narcotráfico, la delincuencia, el paramilitarismo, la religión y el caciquismo (Varela, 1995).

El gobierno de César Gaviria, a través del discurso oficial de la Consejería para la Modernización declaró en crisis el modelo intervencionista, centralista, cerrado y proteccionista de nuestro Estado y justificó la reactualización del ideario liberal en cuanto a filosofía política y doctrina económica. El actual gobierno de Ernesto Samper, aunque pretende suavizar el proceso, "poniéndole corazón a la apertura". lo mantiene, porque como ya se ha dicho, hay una suerte de inevitabilidad, entre otras razones por la nueva lógica del capitalismo financiero mundial, que tiene al FMI y al Banco Mundial como organismos disciplinadores, para reducir el déficit fiscal y garantizar el pago de la deuda externa (Pulecio, 1991).

Se trata pues de volver a una nueva versión del "Estado Mínimo". cuyas funciones esenciales son la administración de justicia y la seguridad para garantizar el ejercicio de las libertades individuales y el disfrute de la propiedad privada como derechos naturales del hombre protegidos por el Estado. Un Estado que sólo es posible, según Locke, mediante una restricción voluntaria de la libertad, apreciación filosófica que retoma la concepción del poder en Hobbes, según el cual el Estado debe ser establecido en nombre del interés de los individuos y de la conservación de la pazy, posteriormente, reforzada en Rousseau, con la concepción del contrato social entre los individuos y la comunidad, materializado en leyes como expresión de la voluntad general, cuya vigencia garantiza la igualdad y de la cual depende, a su vez, la armonía de la sociedad (Varela, i995,b).

En el campo económico, se reactualizan las tesis de Adam Smith, según las cuales los ideales de libertad económica contribuyen al logro de la prosperidad de la sociedad pues las leyes económicas obran en tal forma, que el individuo al buscar su propio provecho, fomenta el 
bienestar general y el desarrollo justo de la sociedad, dejando al Estado la función suprema de "gendarme" ya que en dicha lógica le corresponde al mercado asignar los recursos productivos y sociales y regular el sistema económico, que logra automáticamente a través del sistema de precios.

Bajo estos fundamentos asistimos al actual desmoronamiento o agotamiento del modelo de Estado Intervencionista (proceso que ha sido denominado eufemísticamente de modernización o que otros llaman de privatización del Estado) y nos instalamos bajo la supremacía del Mercado, paradigma que encarna lo que Furuyama ha denominado "el fin de las ideologías".

En este orden de ideas, la reflexión y la discusión sobre el nuevo modelo de Estado ha privilegiado dos líneas analíticas:

- La económica, en franca referencia a la necesidad de reducir el gasto público y el déficit fiscal y, procurar el mantenimiento de una moneda sana y unos indicadores macroeconómicos que posibiliten una acción más transparente y eficaz del mercado, en su nueva dimensión internacional y global.

- La políica. en referencia a la rearticulación de las fuerzas del Estado y la sociedad civil, la democratización y la necesidad de darle mayor legitimidad al Estado y la búsqueda de la equidad que se debe garantizar a los gobernados para la realización de sus derechos individuales y sociales.

Sin embargo, habría al menos una tercera dimensión, normalmente olvidada o relegada a planos secundarios, pero que también reviste especial trascendencia y es la que se refiere a las consecuencias organizacionales, o sea, aquellas llamadas a dotar al aparato estatal de las capacidades de gestión necesarias para llevar a cabo los nuevos objetivos económicos y políticos.

\section{EL DESPLOME DEL MODELO BUROCRATICO}

Se puede afirmar que con la ruptura del paradigma del Estado de Bienestar también asistimos a un "desplome" del modelo burocrático o de organización clásica en la administración pública. Pero también es 
necesario reconocer que aún no existe otro modelo que lo reemplace a nivel teórico, o que haya sido experimentado con tal éxito que pueda hoy reclamar un estatuto de universalidad. Aunque a la luz de las experiencias conocidas, la tendencia dominante es un modelo que tiene en cuenta las particularidades propias de cada contexto, su historia, estructura socioeconómica, cultura, recursos y problemas, en fin, un modelo tendencial que surge como resultado de una especie de movimiento contestatario, en el que hasta ahora se impone el pragmatismo, el individualismo y la contingencia (Prats, 1994), pues la administración pública en casi todo el mundo está enfrentando nuevos retos que no se pueden resolver con los métodos tradicionales (Cabrero, 1992; Kliksberg, 1993).

Las falencias o fisuras que hoy se cuestionan del modelo burocrático están centradas en su agotamiento e incapacidad para responder por las nuevas demandas generadas por la profundización de los procesos aperturistas, y la internacionalización y globalización que la dinámica capitalista le imponen al sistema económico mundial. Por otra parte, el modelo burocrático clásico también hace crisis frente a la rearticulación de la relación Estado-sociedad civil como resultado de la toma de conciencia de las nuevas agendas de democratización, participación y descentralización necesarias para afrontar los nuevos retos sociales. económicos y ambientales. Finalmente, desde la perspectiva de las teorías de la organización y de las ciencias de la administración, se evidencian otros modos de organización y gestión exitosos que contradicen abiertamente el paradigma burocrático. Para una mejor comprensión del fenómeno, considero pertinente partir de la caracterización del modelo burocrático.

\section{SIGNIFICACIÓN Y CARACTERÍSTICAS DEL MODELO BUROCRÁTICO}

Ineficiencia, tramitomanía, rutinización, corrupción, ritualismo, politiquería, arbitrariedad, etc., son sinónimos que el uso corriente ha creado para referirse en términos peyorativos a la burocracia y, además. describiéndole como un fenómeno que se circunscribe sólo a las organizaciones de naturaleza público-estatal. Sin embargo, en las esencias 
de su concepción teórica y metodologica, la organización burocrática tiene una connotación muy diferente.

En primer término, el pionero de la Teoría Burocrática, el científico social alemán Max Weber (1864-1920), no propone un modelo de carácter instrumental equiparable al del pragmatismo de sus contemporáneos, F. Taylor en Norteamérica y H. Fayol en Francia, cuyas propuestas son medios técnicos para controlar los procesos de trabajo en una organización y mejorar su productividad. Se trató, en Weber, de un estudio acerca de un fenómeno que en la época se generalizaba dentro del sistema capitalista: el surgimiento y desarrollo de grandes organizaciones para el manejo de negocios privados y de asuntos colectivos de carácter estatal, fijando como referente analítico las causas y los procesos de su reproducción y los factores de su "éxito" frente a otras formas organizativas que habían copado otras etapas de la historia, bajo el dominio de otras lógicas (basadas en la tradición y en el carisma), diferentes a la creciente racionalidad de la vida en la civilización occidental y de la economía de mercado (Dávila, 1992), como correlato del proyecto de modernidad.

Otro aspecto que debe mencionarse es que los "tipos ideales" en Weber son construcciones metodológicas para estudiar las diferentes formas de autoridad y dominación y las características de la burocracia. No se trata de "ideales" en el sentido normativo o del deber ser, sino de categorías analíticas para aprehender la realidad empírica y constatar en ella la presencia de tales atributos. Lamentablemente, el uso corriente ha distorsionado esta contribución y la ha tomado en el sentido prescriptivo, es decir, que para que una organización sea más eficiente se debe "burocratizar" por considerarla una forma organizativa superior a las demás.

La condición de superioridad de la organización burocrática está fundada en que ella está legitimada, según Weber (1974), por un tipo de "autoridad racional legal que descansa en la creencia de la legalidad de las ordenaciones estatuídas y de los derechos de mando de los llamados por esas ordenaciones a ejercer la autoridad", en contraposición a los otros tipos "puros" de formas organizativas, fundadas en dominación de tipo carismático o tradicional. Aquella racionalidad legal es entendida como el proceso mediante el cual reglas y procedimientos explícitos. 
abstractos, intelectuales y calculables, sustituyen gradualmente a los sentimientos, las tradiciones y la intuición.

Tomando a Dávila (1992), Aktouf (1989) y Etzioni (1965), se entiende que cuando Weber describe las características del tipo ideal de organización burocrática, lo presenta comoel tipo más puro de dominación racional-legal y dotada de superioridad técnica sobre cualquier otra forma de organización, porque:

- Opera con continuidad basada en normas legales y reglas técnicas escritas y estandarizadas.

- Delimita esferas de competencia o jurisdicción precisas y detalladas como parte de una división sistemática del trabajo, los derechos y el poder.

- Distribuye las actividades regulares de modo fijo como deberes oficiales.

- Provee a los titulares de los cargos de la autoridad y los medios compulsivos necesarios para desempeñar sus funciones.

- Somete el uso de la autoridad a condiciones normatizadas previamente difundidas.

- Existe una rígida estructura jerárquica funcional de super y subordinación para garantizar la supervisión y el control.

- Exige entrenamiento especializado para la aplicación de las normas y reglas a las situaciones de los deberes oficiales, cuyo acatamiento garantiza el logro de los objetivos.

- Separa la actividad oficial y la actividad privada de los funcionarios.

- Selecciona y promueve a sus funcionarios por exámenes y méritos en un sistema de carrera.

- Registra por escrito y archiva los actos administrativos, las decisiones y las normas.

- Responde impersonalmente y con neutralidad afectiva ante los usuarios y demás miembros de la organización como resultado del profesionalismo de sus funcionarios.

- Instala a los funcionarios, sus medios materiales y archivos en oficinas.

- Separa al cuerpo funcionarial de la propiedad de los medios administrativos e instrumentos de producción. 
- Remunera a los funcionarios con un salario en dinero según el nivel del cargo.

Desde los más variados campos de las ciencias sociales se han formulado enormes críticas a la burocracia. Crozier (1963) señala que es un sistema de organización incapaz de corregirse en función de sus errores y cuyas disfunciones se convierten en uno de los elementos esenciales de su equilibrio interno. Por su parte Merton (1964) describe cómo la estricta observancia de las reglas que exige la burocracia le impide adaptarse a circunstancias no previstas específicamente y por ello, los mismos elementos que conducen a la eficacia general conducen a la ineficiencia en casos específicos. Veblen se refiere a la "incapacidad adiestrada" como uno de los elementos más visibles del fenómeno burocrático. Bennis (1966), desde la ciencia del comportamiento, critica a la burocracia por su rigidez y por no ajustarse a las "realidades contemporáneas" frente a las cuales están emergiendo nuevas formas de organización. En fin, esta abundante literatura crítica podría resumirse citando a García-Pelayo (1974) quien formula una concepción alternativa de la burocracia como "un sistema de racionalidad y funcionalidad aparentes $y$ de arbitrariedad y disfuncionalidad reales, cuyo resultado es la ineficacia, y caracterizado por actuar con un formalismo ignorante de la realidad, por la sumisión de lo concreto real a abstracciones desvitalizadas, por la pedantería (detallismo), por la rutina administrativa (ritualismo), por la dilación en las resoluciones, por la evasión de responsabilidad y la sumisión dogmática a los criterios de la superioridad o del precedente":

También desde la ciencia política se han enfilado serias críticas a la burocracia. García-Pelayo (1974) relaciona tres modelos que expresan el papel de la burocracia frente al poder:

- La burocracia como "instrumento": cuerpo subordinado rigurosamente a las instancias de decisión política, vinculados no sólo por vínculos jurídicos sino de lealtad (ética), del cual se vale la élite dominante para la reproducción del sistema.

- La burocracia como "usurpadora": cuerpo que acumula, formal o fácticamente los poderes de decisión política y dirección administrativa, de tal manera que la trilogía del sistema anterior. 
gobernantes-burocracia-gobernados, se convierte en la dualidad burocracia-gobernados.

- La burocracia como "saboteadora": cuerpo que al preparar los supuestos de la decisión política y articular su ejecución, los desvía en un sentido diferente al del contenido de la decisión y a la intencionalidad del decisor, o también cuando aplica tan rigurosamente los formalismos jurídico-burocráticos que desvirtúa la decisión o la hace irrealizable, bien porque la consideren atentatoria contra los fines del Estado o de sus propios intereses.

La forma burocrática de organización mantuvo su vigencia y su "esplendor" en el Estado de Bienestar, cuando por su lógica intervencionista y con la equívoca interpretación y aplicación de los postulados keynesianos que le otorgaban al Estado un rol estelar en la generación de empleo, las burocracias se expandieron hasta los niveles de insostenibilidad que el nuevo modelo de Estado le reclama por su alto costo e ineficacia. Pero no es ésta la línea de la discusión que se pretende abordar en el presente artículo; pensamos como Osborne (1994) que el problema no reside en la gente que trabaja en las organizaciones públicas, sino en los sistemas en los cuales trabajan.

\section{INSUFICIENCIAS DEL MODELO BUROCRÁTICO FRENTE AL NUEVO MOdELO dE Estado}

De las diversas críticas que se han formulado al sistema burocrático de organización del sector público, hemos seleccionado, por su importancia, dos problemas que tocan con sus fundamentos estructurales: el referido a la racionalidad legal y el del principio jerárquico, los cuales analizaremos con algún detalle, pero en un capítulo posterior se contrastarán a menor espacio las líneas del modelo tendencial de la nueva organización pública, frente al modelo tradicional.

\section{A. El problema de la racionalidad legal}

Uno de los aspectos centrales del cuestionamiento al modelo burocrático versa sobre la vigencia de la Racionalidad Legal como valor legitimador único y suficiente de la acción y la gestión administrativa 
pública. Es la confusión entre administración pública y derecho administrativo, que tiene como raíz histórica la transformación del Estado Absolutista, de tipo monárquico y teocrático, hacia el llamado Estado de Derecho, fundamentado en el constitucionalismo y legitimado en la creencia de la Ley como reguladora de la conducta de los gobernados por lo que le corresponde al Estado hacerla cumplir para promover y garantizar los valores fundamentales de la sociedad: la libertad individual. la propiedad privada, la igualdad y el derecho a elegir y ser elegido. En tal contexto, el criterio paradigmático de evaluación de la gestión es la legalidad, valor que subordina la Administración a la Ley y al Derecho, donde aquélla está instituida para la aplicación de las normas generales ( $\mathrm{y}$ del derecho administrativo como disciplina matricial) a situaciones particulares. Otros valores como los de la eficacia y eficiencia en la gestión, siempre figuraron como "adornos retóricos o parientes pobres" del valor legitimador fundamental (Prats, 1994). Lo importante, entonces, no es el cumplimiento de metas o proyectos, ni la productividad de los recursos aplicados, sino el respeto a las normas, cuyo acatamiento o cumplimiento supone el alcance de los objetivos del Estado, a la manera de una condición de isofinalidad.

Este carácter iuscéntrico del Estado, también termina imponiéndose sobre una de las expresiones más sofisticadas de la evolución de la formas burocráticas: la tecnocracia, surgida de la irrupción de la llamada "civilización tecnológica" a mediados del presente siglo, portadora de una nueva racionalidad cimentada en el desarrollo de la ciencia y la técnica. Muchas de sus vertientes tributan a la corriente de la Administración para el Desarrollo que promueve y difunde-años sesentaslas "técnicas modernas de gestión" entre las cuales se destacan: la dirección por objetivos, la planificación y el presupuesto por programas, la organización y métodos, las técnicas de redes para la programación y el control, los modelos econométricos, los métodos cuantitativos y cibernéticos para la toma de decisiones, etc., implementados con gran auge por las grandes corporaciones privadas, pero en las organizaciones públicas, esta racionalidad emergente portadora de nuevos valores, sucumbe ante la racionalidad legal. 
El cuestionamiento actual no es que con la ruptura del Estado de Bienestar, que es también la ruptura con la lógica incrementalista del gasto público, pierda importancia el valor de la racionalidad legal, sino que es insuficiente y necesita ser complementado con otros valores portadores de una nueva legitimidad más acorde con las lógicas y trayectorias dentro de las cuales están evolucionando las sociedades. Por una parte, hay una nueva conciencia social y política que tiene como valores fundamentales la participación, la democratización y la equidad. Algunos analistas y estudiosos de la realidad latinoamericana (Kliksberg, 1993; Ozslack, 1992; Motta, 1991 y otros) consideran que sin esos valores no es posible salir de la crisis, y que la Reforma del Estado se debe plantear en términos de un proyecto político de modernización que aliente nuevas formas de intermediación política, así como la búsqueda y concreción de mayores capacidades para direccionalizar el cambio hacia una mayor participación de la sociedad civil en la toma de decisiones (Vignolo, 1993; Subirats, 1988).

Por otra parte, la tendencia de inseparabilidad entre modernización del Estado y políticas económicas ha rejerarquizado los valores de economía, eficiencia, eficacia y efectividad. En efecto, parece que no hay una lógica intrínseca propia de los proyectos modernizadores, sino que las líneas fuertes del cambio cobran sentido cuando se asocian con objetivos de naturaleza económica (Lahera, 1993: Cavarozzi, 1992).

Estos nuevos valores, como en el caso colombiano, han adquirido estatus jurídico. En nuestra nueva Constitución Política el mandato para la Función Administrativa señala que ésta "debe desarrollarse con fundamento en los principios de... eficacia, economía, celeridad..." (Cap.5, art.209) y, para citar un ejemplo, en el desarrollo legal de los preceptos constitucionales referidos a la prestación de servicios públicos domiciliarios, la Ley 142 de 1994 determina como principios generales (art.2o.), entre otros: prestación eficiente, garantía de calidad, ampliación de coberturas, obtención de economías de escala, libertad de competencia, prestación ininterrumpida, etc.

Dentro de la rejerarquización de lo económico como valor legitimador de la acción estatal son muchas las líneas de cambio que se están experimentando, unas con impactos directos en la reducción del gasto 
público (aplicando políticas de privatización, concesión, desmonte de monopolios, etc.), otras con el propósito de hacer más efectiva la acción de los organismos estatales (contratación externa de ciertos servicios, mejora en los sistemas de contabilidad e información de costos, auditorías de eficiencia, revalorización de la gerencia pública, redimensionamiento para afrontar la competencia abierta a otros actores, promoción del espíritu empresarial dentro de los entes públicos, incentivos por buen desempeño, cambios en la concepción y relación con los usuarios, cobro por los servicios de mérito, etc.) todos ellos encaminados a optimizar la ecuación "Hacer Más con Menos".

Esta nueva racionalidad conlleva un cambio sustancial en el modelo organizacional, porque el burocrático-tradicional resulta insuficiente para asumir las nuevas responsabilidades, entender y adaptarse proactivamente a los cambios rápidos y drásticos del entorno, enfrentar la competencia con otros actores prestadores u operadores de servicios, abrirse a las auditorías ciudadanas e institucionales con nuevos criterios de evaluación, actuar con otras lógicas, comprender al aparato estatal como un creador y promotor del mejoramiento de condiciones sociales y económicas antes que un mero prestador de servicios, revalorizar a sus miembros como actores dotados de humanidad y talento antes que como agentes ejecutores de órdenes y funciones que actúan mecánicamente motivados por un salario y otras prebendas. Otro aspecto de la discusión en el plano de los nuevos valores económicos es el planteamiento acerca de si las medidas de evaluación convencionales de economía (relación entre costos previstos y costos reales), eficiencia (relación entre costos reales y productos obtenidos), eficacia (relación entre productos proyectados) y efectividad (relación de eficacia con la eficiencia), se pueden aplicar de la misma manera que en el sector de los negocios privados.

A este respecto las críticas replican que tales conceptos son insuficientes para medir el verdadero valor de una organización pública y que un programa de cambios sustentados en esa concepción simplificada resultaría trunco porque estaría centrado en la simple reducción del gasto público, o sea, en uno solo de los términos de la ecuación ya expuesta. 
La realidad de la acción administrativa pública no es equiparable a la privada, ya que cuentan diferencias intrínsecas y especificidades (tales como la dificultad de establecer marcos de acción y objetivos precisos; mayor complejidad, contradicción y voluntarismo de los fines de las organizaciones públicas; su inevitable relación con la política; la implicación de los aspectos legales; la dificultad de medir algunos costos indirectos y sociales, lo mismo que para inedir los impactos y beneficios derivados de sus productos), aspectos comúnmente tomados por algunos críticos como las patologías y disfuncionalidades que deben ser corregidas. Pero en este punto cada vez va siendo mayoritario el consenso de que "La administración pública y la administración privada se parecen exactamente en todo aquello que no es importante" (Sayre's). Lo anterior no significa de ningún modo que a la organización pública no deba ni pueda pedírsele eficiencia y eficacia (es preciso recordar que toda ineficiencia tiene también sus propios beneficiarios); el asunto es que se debe evaluar con otros conceptos complementarios tales como la eficiencia técnica, la operacional, la económica y la organizacional, referida esta última a ideas tales como la innovación, la adaptabilidad a los cambios del entorno, el aprendizaje organizacional y la capacidad para gestionar el cambio. (Prats, 1994). Sobre este tópico, central en la nueva conceptualización de gerencia pública, volveremos con otro trabajo que actualmente está en preparación.

En síntesis, se trata de entender al sector público no como un simple prestador de servicios, sino como un creador de condiciones sociales y económicas globales (Kliksberg, 1993).

\section{B. El problema del principio jerárquico}

Otro de los grandes pilares sobre el cual está construido el paradigma burocrático y que presenta hoy grandes fisuras es el principio jerárquico. Según este principio, el jefe de una entidad es el sujeto de la responsabilidad política por los actos y resultados de su dependencia, para ello garantiza la subordinación de las unidades inferiores donde se inician y realizan todos los procedimientos y actuaciones, pero éstos deben culminarse y resolverse en la cúspide de la pirámide jerárquica; es decir, que es el superior jerárquico quien interviene finalmente en todos los actos y procesos. 
La dinámica propia del modelo burocrático resulta insuficiente cuando la organización asume nuevas y más responsabilidades, pues cuando ello sucede aplica una de dos opciones tradicionales: con la primera se incrementa el número de unidades -vertical u horizontalmente- para asumir las nuevas tareas, es decir, mediante pluralización o, la segunda, adscribiendo las nuevas tareas a las unidades ya existentes, es decir, mediante multifuncionalidad. Pero en cualquier caso, la amplitud y variedad de tareas $\mathrm{y}$ actuaciones provoca un estrangulamiento o "Cuello de botella" en los niveles superiores, bien por sobrecarga de trabajo, por la limitada capacidad de la cúspide para procesar y asimilar la información proveniente de tantas actividades variadas e inciertas, lo que conlleva a la concentración en el día a día y el abandono de marcos estratégicos y del largo plazo, o también, por dispersión, por cuanto la responsabilidad sobre sectores que exigen un ámbito decisional único se encuentra distribuido entre órganos ó departamentos diferentes, lo que conduce a la multiplicación de órganos colegiados como instancias de coordinación.

La reacción convencional de la organización clásica para asegurar la coherencia gubernamental y disponer de una capacidad de interyención de la cúspide, impone reglas detalladas paraestandarizar en procedimientos comunes la gestión de los recursos (Presupuesto, personal, contratación, informática, etc...). Pero como no es posible atar a una organización grande y diversa una colección de procedimientos comunes (Motta, 1993), sobrevienen una o varias de las siguientes consecuencias:

a) Se tiende a respetarlos en apariencia o simplemente a ignorarios

b) Se convierten en controles puramente formales, rituales oficticios

c) No garantizan un funcionamiento eficaz, porque se convierten en una limitación y no en apoyo o incentivo para que el funcionario gestione eficazmente. El resultado final es la "asfixia" de los procedimientos que conduce a una "crisis de responsabilidad", evidenciando pues, la ruptura de la pretendida eficacia integradora del principio jerárquico.

La tendencia actual para resolver este síndrome se resume en dos principios aplicados de vieja data en el sector privado y recuperados para el sector público para dar salida a las disfuncionalidades descritas. Tales principios son: 
a. diferenciación, según el cual de acuerdo con la dinámica de los entornos y de los factores contingenciales se pueden crear unidades u organismos (incluso por fuera de la línea), con estatutos de excepción, bajo "Contratos de Responsabilidad" o desempeño pero vinculados orgánicamente e integrados estratégicamente.

b. integración, superando los controles estrictos y detallados o de primer nivel, por otros fundamentados en la estandarización de criterios para tratar problemas homogéneos, otorgando gobernabilidad para enfrentar asuntos que son de alto valor en su nivel pero de bajo valor en la cúspide, y creando culturas organizativas basadas en procesos de planificación estratégica, gerencia creativa y alta responsabilización.

En síntesis, el problema no es la autonomía de gestión sino los mecanismos de integración que garanticen la coherencia de la acción de la dependencia y el aseguramiento de la responsabilidad política. Como Io expresa la Comisión de Reforma del Estado francés, el nuevo reto es "pasar del Estado del procedimiento al Estado de la responsabilidad" (Echebarría, 1994).

\section{MODELO TENDENCIAL V. S. MODELO TRADICIONAL DE ORGANIZACION PUBLICA}

Finalmente, de forma muy esquemática y a manera de conclusión, deseo presentar un paralelo entre el Modelo Tradicional y el Modelo Tendencial de Organización Pública, tomando no sólo lo fundamental de los dos problemas analizados en el apartado anterior, la evolución de las teorías administrativas, organizacionales, de gestión y del comportamiento, sino también las innovaciones más visibles constatadas y en progreso expuestas en varios de sus trabajos por expertos y pensadores de vanguardia en estos tópicos, para citar sólo algunos, Kliksberg, Motta, Ozslack, Matus, Lahera, Cabrero y Escotto, Cavalcanti, en América Latina, y Echebarría, Prats, Osborne, Aktouff, Crozier, Chanlat, en otros contextos.

Actualmente es claro, para reiterar lo afirmado en el numeral 2, que el paradigma burocrático clásico se ha agotado para proveer las capacidades organizacionales requeridas, en concordancia con los nuevos roles del 
Estado. Pero no existe aún otro paradigma que 10 reemplace con pretensiones de universalidad o de modelo ideal. $\mathrm{Y}$ esto tiene una explicación: la concepción de un Estado omnipresente y único actor y agente del desarrollo y el bienestar indujo a que la organización pública fuese cerrada, rígida, altamente formalizada y jerarquizada verticalmente, a cuyo influjo se desenvolvía la sociedad; pero hoy el Estado se piensa como flexible y permeable a los intereses y demandas de la sociedad civil y abierto a las lógicas del capitalismo internacional con sus pretensiones de globalización y sus instancias disciplinadoras. Por lo tanto, la nueva organización pública es contingente frente a sus particulares condicionamientos internos y externos, lo que hace que no puedan buscarse fórmulas ideales que pretendan aplicarse sin reparar el contexto histórico, político y cultural de cada realidad administrativa (Cabrero, 1993; Prats, 1994).

A continuación y para comprender mejor la esencia y alcance de los cambios, enfrentamos las variables organizacionales y sus referentes conceptuales más representativos, tanto del modelo tradicional burocrático como del modelo tendencial de la nueva organización pública. Como se podrá apreciar, la tendencia es "contestataria" (Prats), pero si se quiere, también se podría leer como un proceso dialéctico de rupturas y aperturas, donde cada concepto evoluciona hacia su contrario:

\section{VARIABLE II ESTRUCTURA ORGANIZACIONAL}

MODELO TRADICIONAL

(RUPTURAS)
MODELO TENDENCIAL

(APERTURAS)
- Con las formas piramidales características de la burocracia. donde florecen largas cadenas escalares de mando que empiezan a ampliarse desde el segundo nivel para instalar un SISTEMA DE SUPER y SUBORDINACIÓn donde cada
- Hacia fORMAS PLANAS, que reduzcan los niveles y las disfuncionalidades de los formalismos jerárquicos, que favorezcan el trabajoenequipos y POR PROYECTOS, bien sea a través de:

- estructuras divisionales que 
miembro tiene un jefe a quien debe acatar so pena de sanción y castigo, pero bajo cuyas órdenes también tiene subalternos que deben seguir sus dictados, rematadas en su nivel más bajo con una amplia base de funcionarios como consecuen- cia del EXCESIVO FRACCIONAMIENTO DEL TRABAJO en unidades y subunidades que no sólo genera hiperespecialización sino que también conduce a largos y lentos flujos de tramitación de asuntos que deben resolverse en la cúspide, donde existe la responsabilidad sustantiva y política, con los consiguientes estrangulamientos o "cuellos de botella" y pérdida de la visión de largo plazo por la sobrecarga de trabajo diario y, pérdida de la visión del conjunto por la extrema división de tareas.

Estas cadenas jerárquicas son, con frecuencia, alargadas en la práctica mediante la excesiva diversificación de grados, clases y categorías que por pocos pesos crean denominaciones y subniveles con representación y expresión real de status y jerarquía. reconozcan la diversidad y las especificidades de asuntos o negocios que deben ser manejados con AUTONOMIA bajo marcos estratégicos, de responsabilidad y de direccionalidad concertadas, 0 - estructuras matriciales, especialmente cuando se requiera INTERDISCIPLINARIEDAD y personal muy calificado, o

ESTRUCTURAS VIRTUALES O AD-HOC para la realización temporal de ciertas actividades críticas o estratégicas, o las también llamadas "estructuras de implementación de las políticas públicas".

- En general, la consideración de esquemas de REDES, bajo la comprensión de lo público como una red inter e intraorganizacional, con una connotación más HORIZONTALdonde pueda haber más cercanía entre la alta dirección y la base, los flujos comunicacionales más expeditos en la doble vía, se recuperen los contactos cara a cara $y$ se fomente la polivalencia y el enriquecimiento del trabajo. 
- Con modelos de alta formaLIZActón en los que todo está normatizado y prescrito, tanto las rutinas administrativas como los comportamientos, anulando todo intento de creatividad e iniciativa, y además, padeciendo traumatismos o desgastes cada que aparece una situación no contemplada en los reglamentos.

- Con los roles estables, propíos de la formalidad burocrática, prescritos como FUNCIONES O deberes oficiales dentro de los cuales se delimitan las jurisdicciones O COMPETENCIAS DETALLADAS Y RíGIDAS, Como campos de actuación en los cuales no pueden intervenir otros, salvo que tengan facultad expresamente determinada en las normas.
- Hacia estructuras flexibles que operen dentro de marcos estratégicos amplios, que permitan la adaptabilidad a las situaciones cambiantes de los entornos, sobre todo en aquellos donde la gobernabilidad es baja o no existe. Acción sobre la base de políticas o criterios que permitan crear opciones cuando se den problemas no estructurados y para estandarizar aquellos que son repetitivos.

- Hacia roles cambiantes y SITUACIONALES establecidos con base en las RESPONSABILIDADES globales y particulares propias de los objetivos o proyectos, que deben evolucionar en relación con los cambios del entorno $y$ de las redesintere intraorganizacionales, entendidas como sistemas ABIERTOS en permanente interacción con el ambiente, que provee oportunidades que deben ser aprovechadas y amenazas que deben ser neutralizadas y reconvertidas en oportunidades. 


\section{VARIABLE II: SISTEMA DE DECISIÓN}

MODELO TRADICIONAL

(RUPTURAS)

- Con los esquemas de pODER DECISORIO CENTRALIZADO en la cúspide de la pirámide burocrática donde se deben resolver todos los asuntos de la organización, donde impera el carácter MONOCRÁTICO (decisión por una sola persona) sustentado por la alta formalización, con la capacidad de veto a cualquier opción presentado o tramitado por un miembro de la organización o por comités o comisiones conformadas para asuntos de todo orden, en los cuales lo más típico es la no decisión, la disolución antes que la resolución del problema, pero con la consiguiente dilución de la responsabilidad, hasta que el problema se vuelva parte del paisaje.

- Con el criterio de legalidad como VALOR ÚNICO para legitimar las decisiones y actos de la administración, donde el APEGO A LA NORMA Y AL PROCEDIMIENTO SON necesarios y suficientes para dar la justificación a la decisión.

\section{MODELO TENDENCIAL}

(APERTURAS)

- Hacia la diversificaCión Y DEMOCRATIZACIÓN DE NÚCLEOS DECISORIOS, dispersos a lo largo y ancho de la organización, con intervención de varios actores (incluso de fuera de la organización o división), donde con un carácter de COLEGIALIDAD se seleccionen, procesen y resuelvan los problemas en la respectivaárea y nivel en que sean de alto valor, se doten de las capacidades correspondientes de movilización de recursos y con ellos puedan ampliar los espacios de gobernabilidad para enfrentar las demandas ciudadanas y las de otros órganos de la macroorganización en la implementación de las políticas públicas.

- Hacia la consideración de otros VALORES COMO la ECONOMIA y LA DEMOCRATIZACIÓN para que acompañen la legalidad en el proceso decisorio, que deben configurar y generar el APEGO A OBJETIVOS, PROYECTOS Y ESTRATEGIAS COMO referentes decisionales y nuevas fuentes de legitimidad. 
- Con el juego subterráneo de interferencia y control producido por las disfuncionalidades burocráticas que surgen de convertir el aparato gubernamental como escenario o arena para dirimir los conflictos de intereses de la lucha política o porque las rigideces del formalismoy las jerarquías niegan a los integrantes de la organización la posibilidad de satisfacer institucionalmente ciertas necenecesidades de carácter individual pero cuya exclusión mengua la higiene $y$ el clima organizacional y conduce a la reproducción de conductas que obstaculizan o reducen la eficacia del análisis de problemas y toma de decisiones.
- Hacia una mayor compatibilización y CERCANIA DE LA ORGANIZACIÓN FORMAL Y LA INFORMAL Para hacer más congruentes los proyectos institucionales con los proyectos colectivos (societales) e individuales, donde el proceso decisorio sea INTERACTIVO, es decir, un escenario abierto a la inclusión y concertación de intereses de múltiples actores participantes del juego social, bajo una dinámica de aproximaciones sucesivas que van construyendo viabilidad política (en el mejor sentido de la expresión) en torno a los macroobjetivos y a las grandes estrategias y políticas, cuya implementación será más fluida al contar con los consensos, el compromiso y los recursos que cada actor participante controla.

\section{VARIABLE III: SISTEMA DE PLANEACIÓN}

MODELO TRADICIONAL

(RUPTURAS)
MODELO TENDENCIAL

(APERTURAS)
- Con los procesos de planeación basados en el criterio y el proyecto político del dirigente, quien le da un carácter IMPositivo que fluye a manera déórdenes e instrucciones DESDE ARRIBA HACIA ABAJO por toda la cadena escalar de la jerarquía y
- Hacia procesos de planeación basados en el consenso y, por lo tanto, con un carácter PARTICIPATIVO Y MULTIDIRECCIONAL, es decir, que no sólo fluyen las ideas, los proyectos y la información desde arriba hacia abajo y viceversa sino 
con toda la fuerza del poder que acumula y puede movilizar la cúspide de la pirámide. No es permitido disentir o controvertir y por ello sólo el tex to de la norma o del procedimiento (exhibidos como recurso de poder) puede neutralizar y obstaculizar las pretensiones directivas.

- Con la unidimensionalidad econóMICA como expresión fundamental y distintiva de los planes; vale decir con la reducción de todos los procesos societales a variables económicas o macro-económicas bajo las cuales se pretende captar -en modelos matematizables o ecuaciones- todos los matices y dimensiones de la realidad.

- Con planes deterministicos y UNIDIRECCIONALES, que señalan un solo camino para el futuro, independiente de los cambios del contexto reflejo de una conceptualización de los patrones de cambio como ESTABLES o bajo la total gobernabilidad del planificador, quien estima que su plan está destinado a cambiar en la medida de sus pretensiones porque es el ESTADO EL AGENTE ÚNICO DEL DESARROLLO, quien direccionaliza la dinámica social. también en forma horizontal, con participación no sólo de miembros de la organización sino también de lared interorganizacional e incluso con actores de otros estamentos y proyectos sociales, políticos $y$ económicos.

- Hacia procesos de planificación que contemplen en forma HoLISTICA y MULTIDIMENSIONAL los diversos aspectos y expresiones de la realidad. En un mundo donde lo económico es un gran motor de la sociedad, la comprensión de sus lógicas no es desestimable, pero deben integrarse con las dimensiones sociales, ecológicas, políticas, institucionales, etc.

- Hacia planes estratéGıcos concebidos bajo el supuesto de que en la realidad interactúan una VARIEDAD DE ACTORES que tienen sus propios proyectos e intereses, que tienen capacidad de planificación y de control de recursos, que pueden contribuir o amenazar la viabilidad del plan gubernamental $y$, por otra parte, ese juego de interacciones es el que moldea el futuro y hay que estar replanificando en forma ADAPTATIVA $y$ PROACTIVA para enfrentar la incertidumbre $e$ inestabilidad de 
los patrones de cambio de la realidad.

- Con planes que pretenden abordar la complejidad de las interacciones sociales como una totalidad única a partir de un DIAGNÓSTICO que pretende aprehender $y$ explicar la realidad bajo la perspectiva de un sólo actor, concepción que entrega como producto final un PLAN-LIBRIO cuya elaboración toma gran parte del período del gobernante y se mantiene RígIDo durante el resto del período, como si la situación no cambiara, lo que en la práctica real se traduce en tener que actuar por fuera del plan, o sea, improvisadamente, y consume mucho tiempo en explicar por qué no se puede cumplir con lo planificado.
- Con planes construidos con base en módulos que corresponden a aquellos PROBLEMAS que el dirigente escoge para enfrentar a partir de su propia EXPLICACIÓN SITUACIONAL, analizando la fuerza y las posibles estrategias de los demás actores que intervienen y pueden controlar recursos críticos en cada ámbito problemático e identificando las márgenes de gobernabilidad y maniobra frente al perfi] estratégico de cada actor, sea éste aliado, indiferente u oponente, pero cuyo apoyo es requisito para la viabilidad del plan y de las operaciones que cada problema exige; en este sentido, planifica quien gobierna y no una oficina independiente.

\section{VARIABLE IV: SISTEMAS DE DIRECCIÓN}

MODELO TRADICIONAL

(RUPTURAS)

- Con los estilos de dirección de perfil aUtocrático, fundados en la jerarquía formalizada, Ia centralización y la dicotomía dirección-administración, es decir, que son los dirigentes los
MODELO TENDENCIAL

(APERTURAS)

- Hacia estilos de dirección de carácter CONSENSUAL, que $\sin$ formalismos y derribando el mito de los conductos regulares, escucha a quien pueda aportar una idea o una observación, estimula la iniciativa. 
que piensan y deciden y el resto del aparato burocrático sólo se debe limitar a obedecery a cumplir con las órdenes, instrucciones y normas que emanan desde la cúspide de la pirámide, configurando un LIDERAZGO CONDUCTISTA, que no sólo prescribe objetivos sino comportamientos, a los cuales hace parte de una disciplina que hay que hacer cumplir con base En SANCIONES Y CASTIGOS que intimidan y someten a individuos y grupos a quienes manda con aires de despotismo, les inspira miedo, los culpa de todo lo que no sale bien porque él es el único que posee todo el saber, en fin, haciendo del trabajo unapesadilla, donde el hombre es otro RECURSO más de esa máquina de pretendida eficiencia superior que es la organización burocrática clásica. la creatividad y los desempeños ejemplares propone objetivos sobre cuya concertación se crean las responsabilidades, es decir, un LIDERAZGO EMPRENDEDOR que Se preocupa por el proceso grupal, orienta, ayuda a solucionar problemas, tranquiliza, guía, inspira entusiasmo, enseña con el ejemplo y promueve el aprendizaje individual y organizacional aprovechando los errores para analizarlos y derivar lecciones antes que sanciones, en fin, haciendo una gerencia de valores constructivos que propicien climas organizacionales más gratificantes que refuercen el compromiso, la responsabilidad, la realización personal y social, es decir, hacer del trabajo una diversión y un autodesafío diario, en el cual el hombre se reconozca como TALENTO y como un fin de toda actividad.

\section{VARIABLE V: SISTEMA DE EVALUACION Y CONTROL}

\section{MODELO TRADICIONAL \\ (RUPTURAS)}

\section{MODELO TENDENCIAL}

(APERTURAS)

- Con el sistema de control basado - Hacia un sistema de control por únicamente en el CUMPLIMIENTO EVALUACION DEL DESEMPEÑo con DE FUNCIONES Y NORMAS, en la creencia de que la celosa base en los "contratos" de responsabilidad previamente 
observación de los reglamentos es suficiente para el logro de los objetivos organizacionales. Para ello es necesaria una estricta vigilancia o SUPERVISIÓN DIRECTA que garantice la sujeción a normas y procedimientos previamente ordenados y formalizados, pues no importa la eficacia o la eficiencia sino que se realicen todos los pasos, verificaciones y vistos buenos establecidos a to largo de la cadena de mando, que con frecuencia se convierten en un obstáculo para la acción.

- Con los esquemas de evaluación NUMÉRICO-LEGAL, basados en la revisión formalista de los actos administrativos, y practicados descontextualizadamente por otros ajenos a la responsabilidad sustantiva de la acción y la ejecución. concertados con la dirección, con indicadores que reflejen adecuadamente la contribución de personas y grupos al LOGRO DE OBJETIVOS y estrategias institucionales y que se conviertan en un estímulo para la acción, que conduzcan a una CULTURA DE RESPONSABILIZACIÓN, es decir, transformándose en controles de segundo y tercer grado, para pasar del Estado de los procedimientos al Estado de la responsabilidad.

- Hacia esquemas de AUTOCONTROL, basados en los contratos de responsabilidad, en los que cuentan, no sólo los productos visibles de la gestión, sino los procesos $\mathrm{y}$, más aún, los impactos de los productos de la acción organizacional.

\section{VARIABLE VI: COMPORTAMIENTO}

MODELO TRADICIONAL

(RUPTURAS)
MODELO TENDENCIAL

(APERTURAS)
- Con los modos de comportamiento orientados al DESEMPEÑO DE FUNCIONES $y$ tareas prescritas detalladamente en manuales de procedimientos y organigramas
- Hacia modos de comportamiento orientados al LOGRO DE OBJETIVOS Y PROYECTOS establecidos en los procesos decisorios consensuales, que son los llamados a crear 
formales, que crean un sentimiento de LEALTAD A LA NORMA, la que debe ser internalizada y por lo tanto provee mecanismos automáticos de respuesta REACTIVA cada que alguien o algún acto administrativo pisa sus linderos, porque el deber del funcionario es el respeto y aplicación de las normas generales a casos particulares, $o$ también porque en cada ocasión se refuerza la identidad del EJECUTOR DE ÓRDENES.

- Con el compromiso polftico como vínculo fundamental y cristal a través del cual se observa, se evalúa y se filtra todo lo que acontece en y alrededor de la organización $y$, se reacciona en consecuencia, con una conducta motivada y orientada sólo por todo aquello que convenga a la optimización de los recursos de poder dentro de la organización y para ser usado también fuera de ella en la búsqueda de intereses individuales o personalistas sentimientos de responsabilidad y de PROFESIONALIZACION para alentar su alcance, que estimule la actitud PROACTIVA para mejor aprovechamiento de oportunidades, ocuando algo no está saliendo bien o se perfila una amenaza, se vea ésta como una oportunidad y un reto para crecer individualmente $y$ ayudar permanentemente al mejoramiento institucional y social, es decir, como un verdadero AGENTE DE CAMBIO.

- Hacia un mayor compromiso INSTTTUCIONAL Y SOCIAL, que amplíe la visión y la posibilidad de la interpretación de los fenómenos a la luz de otras racionalidades orientadas hacia la búsqueda de la solidaridad y la equidad como valores esenciales de la gestión de los asuntos colectivos, que acompañen lo político como lealtad única y suficiente para movilizar las decisiones y las acciones. 


\section{VARIABLE VII: PERCEPCIÓN DEL CONTEXTO}

MODELO TRADICIONAL

(RUPTURAS)

- Con la concepción de que LA SOCIEDAD GIRA EN TORNO AL ESTADO, quien tiene el poder y el derecho para direccionalizar todas las interacciones sociales, o sea, que la sociedad se debe al Estado y a sus organizaciones y políticas públicas.

- Con la percepción de que el ESTADO ES EL ADMINISTRADOR DE LOS RECURSOS SOCIALES $\mathrm{y}$, por lo tanto, es él quien se abroga el derecho de disponer y utilizar los recursos según sus propios dictados y según sus propios fines y medios

- Con la creencia de que el ENTORNo ES ESTABLE Y CARGADO DE CERTEZA. que las organizaciones no deben cambiar porque el ambiente en el que se desenvuelven no cambia, pero cuando se percibe un cambio. las variables, sus patrones y los métodos son conocidos y calculables; esta concepción de que la realidad es un juego estructurado y sin sorpresas que permite contar con la SUPERVIVENCIA ORGANIZACIONAL ASEGURADA.

\section{MODELO TENDENCIAL \\ (APERTURAS)}

- Hacia el entendimiento de que las ORGANIZACIONES PÚBLICAS GIRAN EN TORNO A LA SOCIEDAD, o sea, que el Estado se debe a la sociedad y es ella quien fija la dirección, las estructuras, las competencias y los comportamientos de los entes públicos.

- Hacia un concepto más amplio del ESTADO COMO PROMOTOR DE PROYECTOS Y CONDICIONES SOCIALES, que siguen derroteros fijados por las instancias societales y debe procurar su logro bien a través de la acción directa o facilitando el acceso a quienes quieran y puedan hacerlo.

- Hacia la convicción de que el ENTORNO ES DINÁMICO Y CARGADO DE INCERTIDUMBRE, a veces turbulento y lleno de sorpresas, cuyas variables, patrones y método de cálculo y predicción no son todas conocidas, que los sistemas sociales son juegos semiestructurados, donde todo es posible, la organización es CONTINGENTE respecto de múltiples variables y por lo tanto, la suPERVIVENCIA INSTITUCIONAL TAMBIEN ES UN RIESGO. 


\section{BIBLIOGRAFIA}

AKTOUf, OMAR. "La Administracion entre la tradición y la renovación". Mimeo. Universidad del Valle. Cali, (1989).

Bennis, Warren. El Cambio en las Organizaciones. McGraw Hill, México, (1966).

Cabrero, Enrique y Escotto, Teresita. "Evolución reciente de los Procesos de Reforma de la Administración Pública y su efecto en los Modelos Organizacionales". Documento de Trabajo CIDE-Centro de Investigación y Docencia Económicas. México, (1992).

Cavarozzi, Marcelo. La Crisis de la Matriz Estado-Céntrica: Política y Economía en la América Latina Contemporánea. Clad. Caracas, (1992).

Congreso de la RePública de Colombia. Ley 142 de 1994.

Constitución Política de Colombia (1991).

Crozier, Michel. El Fenómeno burocrático. Amorrortu Editores. Buenos Aires, (1963).

Dàvila, Carlos. Teorías Organizacionales y Administración. McGraw Hill, Bogotá, (1992).

ECheBARRÍa, Koldo. "La División de la Administración Pública en los Programas de Modernización Administrativa” (Esade. Barcelona) En: Cárdenas, Jorge (Comp.). Gobernabilidad y Reforma del Estado. Biblioteca Jurídica Dike. Bogotá, (1994).

Etzloni, Amital. Organizaciones Modernas, Uthea. México, (1965).

García-Pelayo, Manuel. Burocracia y Tecnocracia. Editorial Alianza. Madrid, (1974).

Kliksberg, Bernardo. Cómo transformaral Estado. Fondo de Cultura Económica. México, (1993).

Lahera, Eugenio. "Políticas Públicas: Un Enfoque Integral". En: Lahera, E. (Editor). Cómo Mejorar la Gestión Pública. Cieplan-Flacso. Chile, (1993).

Merton, Robert K. Teoría y Estructura Social, Fondo de Cultura Económica. México (1964).

Motta Paulo R. La Ciencia y el Arte de Ser Dirigente. Ed. Tercer Mundo. Bogotá, (1993).

Innovación y Democratización en la Gestión Pública. Clad. Serie Temas de Coyuntura. Caracas, (1991).

Oslack, OsCar. La Organización de la Reorganización Estatal: Tendencias en la Reforma del Sector Público en América Latina. Universidad Nacional de Buenos Aires. (1992).

Osborne, David. Reinventando el Gobiemo. Ed. Paidóss. Barcelona, (1994).

PRATS, JOAN. "La Modernización Administrativa en las Democracias Avanzadas" (Esade. Barcelona) En: Cárdenas, Jorge H. (Comp.) Gobernabilidad y Reforma del Estado. Biblioteca Jurídica Dike. Bogotá, (1994). 
Presidencia de la República de Colombia. Programa de Modernización del Estado. Bogotá, 1991.

Pulecio, Reynel. La Apertura Económica. Fescol. Bogotá, 1991.

SubIrats, Joan. "Notas Acerca del Estado, la Administración y las Políticas

Públicas". En: Boletín de Resúmenes. Vol.8, No. 4. Clad. Caracas, (1988).

VARElA, Edgar. Crisis de la Civilidad en Colombia. Centro Editorial Universidad del Valle. Cali, 1995.

Modernidad y Crisis del Interés Público. Mimeo. Universidad del Valle. Cali, (1995, b).

Vignolo, Carlos, et al. "Modernización de la Gestión Pública". En Lahera, E.

Cómo Mejorar la Gestión Pública. Cieplan-Flacso. Chile, (1993).

Weber, Max. ¿Qué es la Burocracia? Amorrortu Editores. Buenos Aires, 1974. 